\title{
STATE STRATEGIES FOR INTEGRATING PHYSICAL AND BEHAVIORAL HEALTH SERVICES IN A CHANGING MEDICAID ENVIRONMENT
}

Deborah Bachrach, Stephanie Anthony, and Andrew Detty Manatt, Phelps \& Phillips, LLP

AUGUST 2014

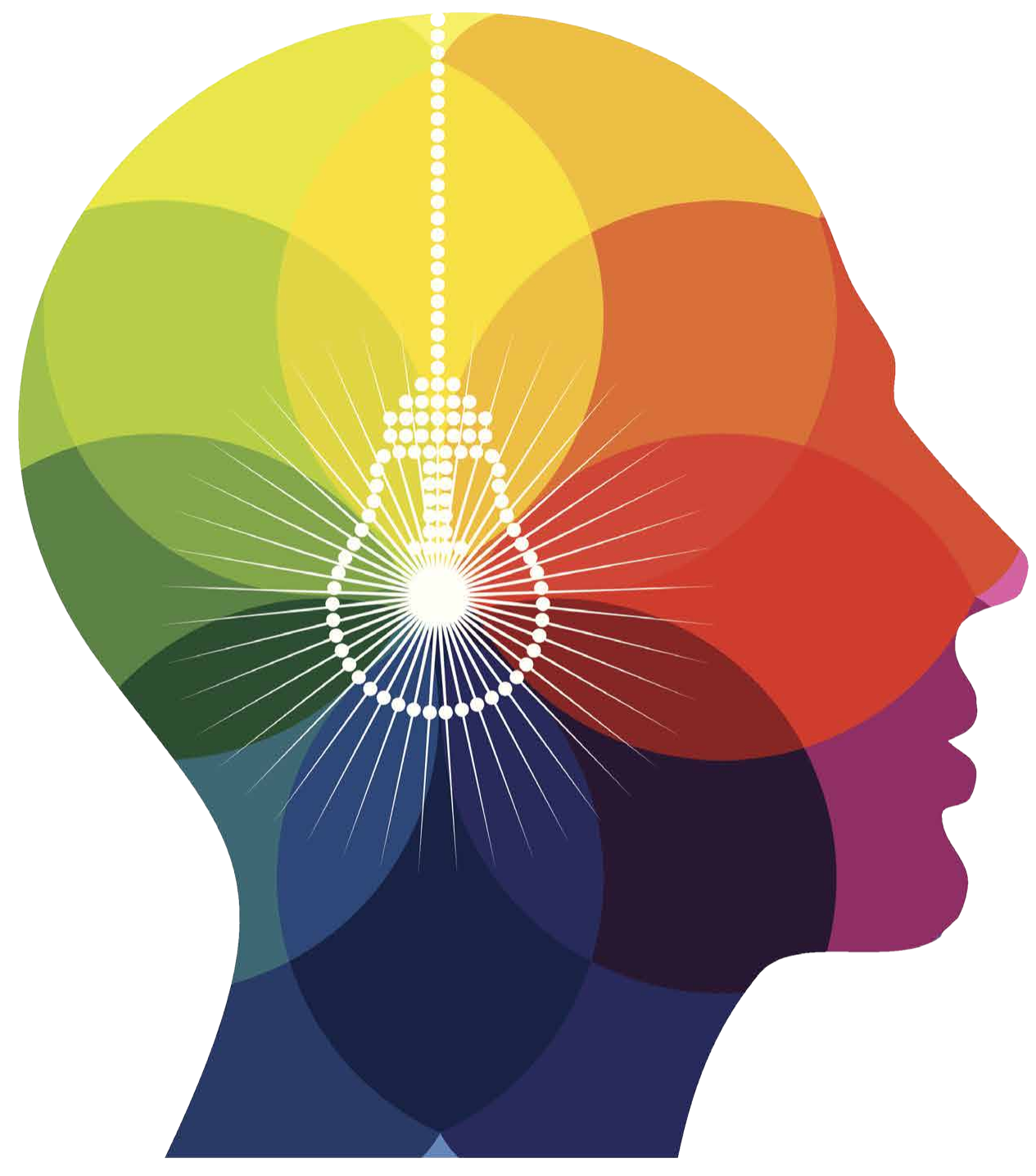


The Commonwealth Fund, among the first private foundations started by a woman philanthropist-Anna M. Harkness-was established in 1918 with the broad charge to enhance the common good.

The mission of The Commonwealth Fund is to promote a high performing health care system that achieves better access, improved quality, and greater efficiency, particularly for society's most vulnerable, including low-income people, the uninsured, minority Americans, young children, and elderly adults.

The Fund carries out this mandate by supporting independent research on health care issues and making grants to improve health care practice and policy. An international program in health policy is designed to stimulate innovative policies and practices in the United States and other industrialized countries. 
The

COMMONWEALTH

FUND

\title{
STATE STRATEGIES FOR INTEGRATING PHYSICAL AND BEHAVIORAL HEALTH SERVICES IN A CHANGING MEDICAID ENVIRONMENT
}

\author{
Deborah Bachrach, Stephanie Anthony, and Andrew Detty \\ Manatt, Phelps \& Phillips, LLP
}

AUGUST 2014

\section{ABSTRACT}

States across the country are embracing integrated care delivery models as part of their efforts to deliver high-quality, costeffective care to Medicaid beneficiaries with comorbid physical and behavioral health needs. The Medicaid expansion authorized by the Affordable Care Act brings greater import to these efforts, as millions of previously uninsured low-income adults, many at increased risk for behavioral health conditions, gain coverage. State efforts to ensure that Medicaid beneficiaries have access to integrated care, however, are hindered by a fragmented behavioral health system that is administered and regulated by multiple state agencies and levels of government, and by purchasing models that segregate behavioral health services from other Medicaid-covered services. Drawing on a review of the literature and interviews with consumers, providers, payers, and policymakers, this report explores strategies states are deploying to address or eliminate system-level barriers to integrated care for this medically complex and high-cost Medicaid population. 


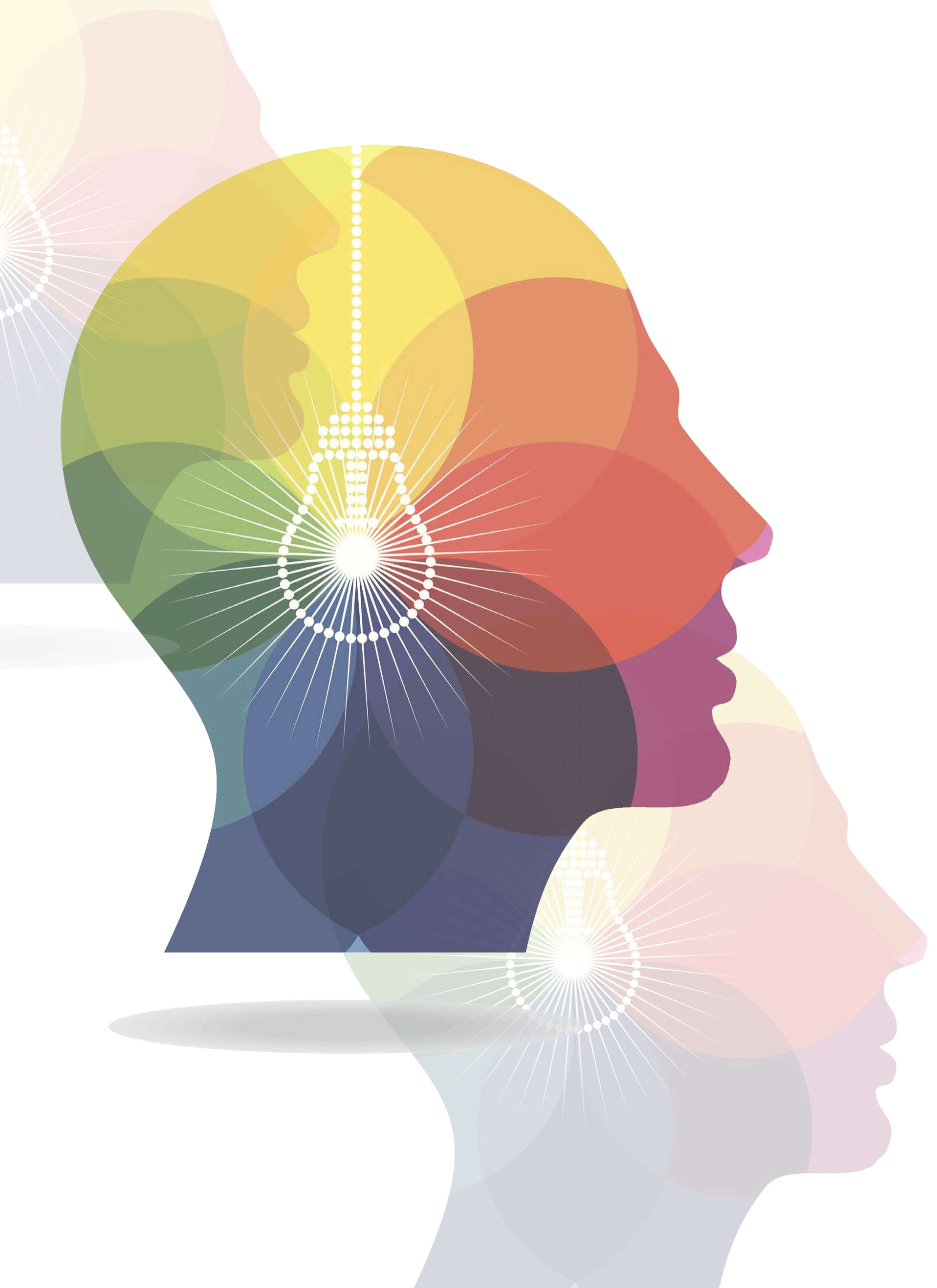




\section{CONTENTS}

About the Authors 6

$\begin{array}{ll}\text { Acknowledgments } & 6\end{array}$

$\begin{array}{ll}\text { Executive Summary } & 7\end{array}$

$\begin{array}{lr}\text { Introduction } & 9\end{array}$

Core Attributes of Integrated Care Delivery 9

$\begin{array}{lr}\text { Administrative Structures and Strategies } & 10\end{array}$

$\begin{array}{ll}\text { Purchasing Strategies } & 11\end{array}$

$\begin{array}{ll}\text { Regulatory Requirements } & 14\end{array}$

$\begin{array}{ll}\text { Conclusion } & 16\end{array}$

$\begin{array}{ll}\text { Notes } & 17\end{array}$ 


\section{ABOUT THE AUTHORS}

Deborah Bachrach, J.D., is a partner at Manatt, Phelps \& Phillips, LLP. She has more than 25 years of experience in health policy and financing in both the public and private sectors and an extensive background in Medicaid policy and health care reform. She works with states, providers, and health plans in implementing federal health reform and Medicaid payment and delivery system reforms. Ms. Bachrach has served as an advisor to the Center for Health Care Strategies, the Medicaid and Children's Health Insurance Program (CHIP) Payment and Access Commission, the Robert Wood Johnson Foundation, and the Kaiser Family Foundation as well as state Medicaid agencies, foundations, health care providers, and other health care organizations. From 2007 to 2010, Ms. Bachrach was the Medicaid director and deputy commissioner of health for the New York State Department of Health, Office of Health Insurance Programs. She received a B.S. from the University of Pennsylvania, Wharton School, and a J.D. from New York University School of Law.

Stephanie Anthony, J.D., M.P.H., is a director at Manatt Health Solutions, a division of Manatt, Phelps \& Phillips, LLP. She has over 17 years of experience providing health policy and health law research, analysis, and advisory services to publicand private-sector clients. Her areas of focus include state and national health care reform, Medicaid and CHIP financing and waivers, long-term services and supports, and coverage options for the uninsured. Most recently, Ms. Anthony was a principal associate with the Center for Health Law and Economics at the University of Massachusetts Medical School. From 2004 to 2008, Ms. Anthony was the deputy Medicaid director in the Massachusetts Executive Office of Health and Human Services, where she was integrally involved in the development and implementation of the Commonwealth's landmark health care reform law. She received a B.A. from Boston College, a J.D. from St. John's University School of Law, and a M.P.H. from Yale University School of Medicine, Department of Epidemiology and Public Health.

Andrew Detty is a senior analyst at Manatt Health Solutions, a division of Manatt, Phelps \& Phillips, LLP. Mr. Detty's primary areas of focus include advising public- and private-sector clients on federal-state collaborative health initiatives, public health insurance programs (Medicare, Medicaid, and CHIP), federal and state health policy trends, and health care provider markets. Most recently, Mr. Detty worked for the United Hospital Fund, where he conducted research and prepared analyses on New York Medicaid policy and health coverage, including analyses of new care delivery and financing models for high-cost, high-need Medicaid populations, as well as reporting on trends and geographic patterns in public and private insurance coverage.

\section{ACKNOWLEDGMENTS}

The authors would like to thank Pamela Riley, M.D., M.P.H., assistant vice president for The Commonwealth Fund's Delivery System Reform program, for her support and guidance throughout the development of this report. The authors also sincerely thank all members of the project's Advisory Group (below) for their generous commitment of time and expertise, and invaluable contributions to the development of this report.

David I. Cohen, M.D.

Maimonides Medical Center

Mary Giliberti

NAMI (National Alliance on Mental Illness)

Allison Hamblin

Center for Health Care Strategies

Charles Ingoglia

National Council for Behavioral Health

MaryAnne Lindeblad

Washington State Health Care Authority
Ellen Meara

The Dartmouth Institute for Health Policy and Clinical Practice

Kathleen Nolan

National Association of Medicaid Directors

Joseph Parks, M.D.

MO HealthNet Division, Missouri Department of Social Services

lan Shaffer, M.D.

Healthfirst

Richard Sheola

ValueOptions

Editorial support was provided by Martha Hostetter. 


\section{EXECUTIVE SUMMARY}

States across the country are promoting integrated care delivery as part of their efforts to deliver high-quality, cost-effective care to Medicaid beneficiaries with comorbid physical and behavioral health conditions. The Medicaid expansion authorized by the Affordable Care Act (ACA) brings greater import to these efforts, as millions of uninsured low-income adults, many at increased risk for behavioral health conditions, gain coverage and states are required to provide behavioral health services and meet federal parity laws. State efforts to ensure that Medicaid beneficiaries have access to integrated care, however, are hindered by a fragmented behavioral health system that is administered and regulated by multiple state agencies and levels of government, and by purchasing models that segregate behavioral health services from other Medicaid-covered services.

Drawing on a review of the literature and interviews with diverse stakeholders, this report explores strategies states are deploying to address or eliminate system-level barriers to integrated care for this medically complex and high-cost Medicaid population.

\section{Administrative Strategies}

Most states vest responsibility for Medicaid physical health, mental health, and substance use disorder (SUD) services in two or more separate agencies, each with different missions, leadership, expertise, and constituencies. This fragmented administration often leads to misaligned purchasing strategies and conflicting and redundant regulation of physical and behavioral health providers.

Consolidating the various agencies responsible for physical and mental health and SUD services can help, though it can be politically and structurally difficult to implement given longstanding differences in agencies' mission and constituencies. Thus, it is more common for states to consolidate behavioral health purchasing, contracting, and rate-setting in their Medicaid agency and retain licensing and clinical policy in the behavioral health agencies. Where even that level of consolidation is not feasible states rely on informal collaborations to rationalize strategies across agencies. Informal collaborations are the most tenuous as they are dependent on personal relationships among agency leadership and staff.

\section{Purchasing Strategies}

Medicaid managed care is the preferred delivery model in most states. However, few states offer integrated benefits in managed care; most "carve out," or create separate reimbursement streams for at least some behavioral health services. Early decisions to carve out behavioral health services grew out of political, financial, and policy pressures ranging from stakeholder opposition to cost control to concerns about the ability of Medicaid managed care plans to manage behavioral health services. These carve-out arrangements continue despite mounting evidence that they create barriers to care coordination and information-sharing. Cognizant of these issues, states committed to the carve-out model are adopting various policies to create linkages across providers and systems.

At the same time, a growing number of states are implementing fully integrated managed care approaches, in some cases targeted to individuals with serious mental illness.

\section{Regulatory Strategies}

State regulations governing licensure and certification, billing, and health information exchange also can impede the delivery of integrated care. With authority over Medicaid physical and behavioral services vested in separate agencies or offices, state regulation of these sectors is rarely cohesive and frequently redundant or contradictory. Today, states are seeking to streamline their licensing rules and creating credentialing programs for nontraditional providers, such as community health workers and peer counselors, who increasingly play a role in integrated care models. States also are revising their Medicaid same-day visit policies and establishing billing codes for emerging treatments.

Finally, slower rates of adoption of information technology among behavioral health providers and state and federal constraints on sharing behavioral 
health data also can impede integrated care delivery.

State strategies to support greater information exchange include technical assistance funding for electronic health record implementation, policy guidance, streamlined privacy standards, and standardized, multiprovider consent forms.

\section{Looking Ahead}

While Medicaid has long been the dominant payer for behavioral health services and Medicaid beneficiaries with comorbid physical and behavioral health conditions are among the program's most medically complex and costly, state administrative, purchasing, and regulatory structures have not kept pace with best practices in the field. There is a large body of evidence showing that patients fare best when their physical and behavioral health needs are addressed in tandem. There is no single pathway through which all states will be able to achieve integrated behavioral and physical health care; the best strategy or combination of strategies will depend on a state's political and health care environment. However, regardless of the approach, states will succeed only if they put in place a cohesive framework that enables providers to deliver integrated care to Medicaid patients with comorbid physical and behavioral health needs. 
STATE STRATEGIES FOR

INTEGRATING PHYSICAL AND

BEHAVIORAL HEALTH SERVICES

IN A CHANGING MEDICAID

ENVIRONMENT

\section{INTRODUCTION}

Medicaid plays a central role in financing mental health and substance use disorder (SUD) services, accounting for 26 percent of all spending on behavioral health services in this country. ${ }^{1}$ Medicaid beneficiaries with behavioral health conditions are among the program's most medically complex, with health care costs for beneficiaries with comorbid chronic conditions and mental illness 60 percent to 75 percent higher than for those with chronic conditions but without mental illness. Costs for those who also have a substance use disorder are nearly three times higher. ${ }^{2}$ Notwithstanding the level of spending, individuals with serious mental illness die on average 25 years earlier than those without, largely because of preventable chronic physical illness. ${ }^{3}$

Against this background, it is not surprising that nearly all states have embarked on efforts to improve health outcomes and better manage costs for beneficiaries with comorbid physical and behavioral health conditions. The imperative to rethink payment and delivery of behavioral health services is even more profound in states that have expanded Medicaid coverage as authorized by the Affordable Care Act (ACA). ${ }^{4}$ The expansion population is a diverse group of low-income adults, including many at increased risk for behavioral health conditions. ${ }^{5}$ Moreover, the ACA requires states to provide mental health and SUD services to adults covered under the Medicaid expansion, and to do so in parity with physical health services. By contrast, behavioral health services are optional for preACA covered adults and the Mental Health Parity and Addiction Equity Act for the most part does not apply. ${ }^{6}$ Medicaid expansion brings greater urgency and import to states' efforts to purchase high-quality, costeffective, integrated care for beneficiaries with comorbid physical and behavioral health conditions. However, these efforts often are hindered by a fragmented physical and behavioral health system that is administered, regulated, and financed by multiple state agencies and levels of government; by purchasing models that segregate behavioral health services from other Medicaidcovered services; and by the absence of a cohesive provider community sharing aligned incentives.

This report examines the features of successful integrated delivery models, the state policies and practices that create barriers to integrated care, and steps states are taking to break down those barriers and promote the delivery of integrated care.

\section{CORE ATTRIBUTES OF INTEGRATED CARE DELIVERY}

States across the country are embracing integrated care delivery as part of their efforts to deliver high-quality, cost-effective care to Medicaid beneficiaries with behavioral health needs. The prevalence and interacting effects of comorbid mental illness, substance use disorders, and physical health conditions are well documented, as is the high cost of care for Medicaid beneficiaries with comorbid physical and behavioral health conditions. ${ }^{7}$ Additionally, a growing body of evidence indicates that integrated care delivery models can be cost-effective and improve health outcomes. ${ }^{8}$

A review of the literature ${ }^{9}$ and interviews with consumers, providers, managed care entities, and policymakers identify the following features as key to the delivery of effective integrated care.

\section{- Accountability for the whole person. A single} provider, care team, or health care entity is responsible for coordinating or delivering the full spectrum of physical and behavioral health services and, to the extent applicable, long-term services and supports and social services, such as assistance with housing and employment.

- Aligned financial incentives. State purchasing models, payment policies, and contracting 
requirements for Medicaid physical and behavioral health services are aligned.

- Information-sharing. Provider practices have the health information technology to communicate and exchange information in nearly real time on patient conditions, care, and outcomes with other providers, patients, and their families; managed care entities; and states. State privacy rules enable informationsharing to the maximum extent practicable.

- "Up-to-date" state licensing, credentialing, and billing rules. State licensing, credentialing, and billing rules support best practices on the ground, enabling providers to employ, deploy, and be reimbursed for the range of professionals and paraprofessionals and services required to meet the medical, behavioral health, and social needs of their Medicaid patients.

- Cross-system understanding. Behavioral health and physical health providers are trained in each other's fields to minimize mistrust, lack of understanding, or lack of communication resulting from cultural gaps between the two systems. Individuals with comorbid conditions are treated with respect and compassion, regardless of care setting.

In the next sections we examine state administrative, purchasing, and regulatory strategies and consider how they impede or advance the delivery of integrated care.

\section{ADMINISTRATIVE STRUCTURES AND STRATEGIES}

Administrative responsibility for physical and behavioral health services historically has been split among Medicaid and behavioral health agencies, with different leadership, missions, and staff expertise. Even today, most states vest responsibility for Medicaid, mental health, and SUD services in two or more separate agencies. For example, as of 2010, 48 states had separate Medicaid and mental health agencies, and in 20 of those states, mental health and SUD were in separate agencies. ${ }^{10}$ It is not uncommon to find Medicaid payment and clinical policies and rules for behavioral health services outside the purview of the Medicaid director. ${ }^{11}$

The administrative bifurcation of physical health services and behavioral health services into separate agencies can lead to differences in vision and policy goals and misaligned program priorities, purchasing decisions, and provider regulations. Even where the respective agency leadership recognizes the value of integrated care, the success of such initiatives is highly dependent on personal relationships and a high level of commitment to agency coordination, reinforced by the governor's office.

In addition, separate agencies tend to institutionalize the cultural separation of physical and behavioral health at the provider level, creating different constituencies with competing interests and separate sources of guidance and support at the state level. ${ }^{12}$ As discussed below, states are seeking to address the challenges of separate agency structure in both formal and informal ways.

"I don't know that lawmakers think about integration."

-Maryland provider

\section{Agency Consolidation}

In 2012 and 2013, California eliminated its existing mental health and SUD agencies, transitioning the majority of their responsibilities to the state's Medicaid agency, in order to integrate financing and improve patient outcomes. ${ }^{13}$ The transitions occurred in the context of a state budget deficit and a broad restructuring of California state government, aimed in part at fixing a "haphazard structure that inhibit[ed] coordination and efficiency" because of a lack of cohesion and logical organization. ${ }^{14}$

Agency consolidation directly addresses the challenges that bifurcated administration creates for integrated care delivery, but it can be difficult to accomplish because of the level of upheaval required and longstanding differences in vision, mission, and constituencies among agencies. Consequently, states' use of this strategy is rare. 


\section{Consolidated Contract Oversight}

Many states are addressing the challenges posed by a fragmented administrative structure by consolidating physical and behavioral health purchasing decisions, contracting, and rate-setting in a single agency, while maintaining separate agency structures for licensing and clinical policy.

In 2013, Kansas implemented a new Medicaid managed care program called KanCare, under which Medicaid managed care organizations (MCOs) cover both physical and behavioral health services. To support this shift, Kansas consolidated all Medicaid fiscal and contract management functions in the Kansas Department of Health and Environment (the Medicaid agency) and maintained responsibility for behavioral health policy direction, licensing, and waiver program management in a newly formed, separate Department for Aging and Disability Services. ${ }^{15}$

New York is following a similar approach within its existing agency structure, transitioning ratesetting responsibility for behavioral health services from its behavioral health agencies into its Department of Health (the Medicaid agency). In addition, when the state fully integrates (or "carves-in") behavioral health services into its Medicaid managed care program in 2015, the Department of Health will hold the contract with the managed care plans.

In April 2014, Arizona moved oversight of its physical health service contract for people with serious mental illness in Maricopa County (the state's most populous county, home to Phoenix) from the Arizona Health Care Cost Containment System (the Medicaid agency) to the Department of Health Services' Division of Behavioral Health Services. At this time, the Division began contracting with a regional behavioral health organization (or $\mathrm{BHO}$, a managed care organization that specializes in behavioral health care) to cover physical and behavioral services for this population.

Consolidation of Medicaid purchasing decisions and contracting responsibility in a single agency centralizes administrative and financial accountability and allows clearer policy direction for plans and providers. Agency collaboration remains critical to ensuring
"A system of separate state agencies and constituencies prioritizes the institution over the patient."

-New York State provider

that the responsible agency can tap into the expertise and relationships across the Medicaid and behavioral health agencies. ${ }^{16}$

\section{Informal Collaboration}

Where formal agency relationships do not exist, personalities and personal relationships are key to structuring integrated care models. We see this in Washington State, where the Health Care Authority (the Medicaid agency) and the Department of Social and Health Services (which administers Medicaid behavioral health services) jointly developed requirements for the state's Health Home program, under which MCOs, BHOs, and providers coordinate services across separate physical and behavioral health systems. While the Health Care Authority holds the contracts for Medicaid Health Homes, state officials report that the joint development and its role in stakeholder buy-in were critical to the successful launch of the program. An advantage of such informal arrangements is that they require the least administrative upheaval, compared with the strategies identified above. A disadvantage is that they are the most tenuous since they depend on relationships among agency leadership and staff. ${ }^{17}$

Regardless of the administrative structures by which a state delivers Medicaid physical and behavioral health services, interviewees emphasized the importance of having a clear and consistent strategic vision, goals, and direction across agencies. ${ }^{18}$

\section{PURCHASING STRATEGIES}

The historical bifurcation of Medicaid physical and behavioral health services across multiple agencies can result in different-and uncoordinated-purchasing strategies for physical and behavioral health services.

Of the 35 states that, along with the District of Columbia, provide physical health services through 
Medicaid MCOs in 2014, only nine include all behavioral health services in an integrated benefit package. (One additional state has plans to do so.) The remaining 26 states (plus the District) carve out some or all behavioral health services from their MCO benefit package, providing them through fee-for-service Medicaid, a BHO, or an administrative services organization.

While a small number of states carve out all behavioral health services, most states' coverage varies by service type or Medicaid eligibility category. For example, psychotropic drugs may be included in the MCO benefit package, while treatment for addiction may be carved out. MCOs may cover behavioral health services provided by primary care providers, but not more specialized treatments provided by behavioral health professionals.

As Medicaid agencies gain more experience with managed care and integrated delivery models gain traction, a growing number of states are moving to consolidate their purchasing, so that a single managed care entity holds responsibility for both behavioral and physical health. As important as consolidation is, it does not guarantee integration at the provider level. Potential advantages of carve-in models include the ability to align incentives at the MCO level, availability of comprehensive claims data, and centralized accountability for cost, quality of care, and patient outcomes. ${ }^{19}$ However, in the absence of clear and enforceable contract provisions that require or incentivize integrated care approaches, a carve-in payment approach ultimately may be no more supportive of integrated care than a carve-out approach.

\section{Carve-Outs}

The historical preference for behavioral health carveouts grew from political, financial, and policy pressures ranging from stakeholder opposition to cost control to concerns about the ability of Medicaid managed care plans to manage behavioral health services. Some of these factors continue to have traction among consumers and behavioral health professionals who fear that
"When everyone is responsible [for coordinating care across separately funded systems], no one is responsible."

-Washington State legislative staff person

behavioral health providers and the patients who rely on them will be shortchanged under a carve-in model.

On the other hand, the experience with carveout payment arrangements strongly suggests that they impede the delivery of integrated care. ${ }^{20}$ Strong contract provisions and carefully designed programs help, but rarely provide a completely satisfactory solution. When behavioral health benefits are carved out, accountability for a patient's health requires coordination across two (or even three) managed care or administrative entities that have separate budgets, financial responsibilities, and provider networks. MCOs and payers of carved-out services benefit financially from diverting members to services for which they do not have financial responsibility, potentially resulting in unnecessary or inappropriate referrals and fragmented care delivery. For providers, carve-out models can mean reimbursement models and incentives that do not align across payers (such as when physical health is paid on a capitated basis and behavioral health on a fee-for-service basis).

Carve-outs also complicate informationsharing and service coordination. With separate entities managing individuals' physical and behavioral health care, providers' access to comprehensive patient data often is limited. Responsibility for pharmaceuticals can be particularly confounding; limited access to prescription drug records across systems impedes medication reconciliation, which can lead to severe adverse clinical outcomes. While MCO, BHO, and administrative services organization contracts frequently include requirements to coordinate and share information across separate systems, ${ }^{21}$ such requirements are challenging to enforce and more often than not ineffective. In addition, for consumers and their families, carve-outs create a complex system with multiple points of contact for accessing services and no single entity responsible for meeting the totality of an individual's needs. Despite 
these drawbacks, carve-outs remain the predominant purchasing model for Medicaid behavioral health services. Cognizant of these shortcomings, states that maintain carve-out models are adopting strategies to address these concerns.

\section{Financial alignment and shared accountability.}

Financial alignment - the use of financing mechanisms to create incentives for providers to integrate care-is a critical strategy in a carve-out environment. For example, starting in 2015, Maryland will contract with an administrative services organization to manage carvedout mental health and SUD services for Medicaid beneficiaries. A portion of the organization's payment will depend on its performance on physical health quality metrics, such as all-cause readmission rates and the percentage of patients with an annual primary care visit, thereby tying reimbursement to effective management of both physical and behavioral health services. ${ }^{22}$

\section{Health Homes. The Medicaid Health Home} option under Section 2703 of the ACA offers another mechanism for states with carve-out models to coordinate and manage care across delivery systems. Health Homes provide care management and coordination services to Medicaid beneficiaries with chronic conditions, including behavioral health conditions, ${ }^{23}$ and can be deployed to connect services across managed care plans, $\mathrm{BHOs}$, and fee-for-service Medicaid.

\section{"Without a dedicated funding stream for} coordination, it is difficult to bridge [separate] systems."

-Washington State county social services manager and chemical dependency coordinator

\section{Carve-Ins}

A number of states are moving to add behavioral health services to their managed care benefit package, having concluded that carve-ins provide the best opportunity to facilitate integrated care at the provider level. By centralizing accountability for patient outcomes, quality, and cost of care in a single entity, carve-in purchasing arrangements create an incentive for managed care entities to support, and for providers to deliver, integrated care.

New Mexico implemented a full carve-in arrangement in January 2014. As New Mexico's Medicaid waiver submission reads, "integration of behavioral health and physical health ... is an opportunity for New Mexico to achieve better health outcomes as one entity will be responsible for managing care for the whole person." ${ }^{24}$ New York, which currently carves out most behavioral health services, will implement its carve-in to MCOs in 2015. State officials note that under the current arrangement, beneficiaries "bounce" between care settings, receiving care that is inefficient and inattentive to patients' needs. ${ }^{25}$ Washington State, which currently provides physical health, mental health, and SUD services through three separate systems, enacted legislation in April 2014 authorizing Medicaid to jointly procure all physical and behavioral health services through MCOs or BHOs, beginning in April $2016 .{ }^{26}$

As noted above, a carve-in purchasing model does not guarantee integrated delivery of care. The benefits can be diluted when an MCO subcontracts with a $\mathrm{BHO}$, particularly in the absence of strong contract provisions and oversight. ${ }^{27}$ Stakeholders raise two additional concerns: first, that BHOs' administrative costs divert funds from behavioral health services; ${ }^{28}$ and, second, that MCOs lack the expertise to manage care for people with serious mental illness and SUDs. As discussed below, states have pursued a number of strategies to ensure that carve-in models advance integrated care delivery.

\section{Contract requirements and financing provisions.}

New Mexico includes a provision in its MCO contracts prohibiting subcontracts with $\mathrm{BHO}$ on an at-risk basis. ${ }^{29}$ This arrangement allows MCOs to subcontract with such organizations to leverage their expertise in areas such as utilization management and coordination of care, while ensuring that MCOs remain financially responsible for behavioral health services. Tennessee, another carve-in state, allows MCOs to subcontract for management of behavioral health services, but requires 
"When MCOs entered into risk-based contracts with $\mathrm{BHOs}$, funds were eaten up on the administrative side, and behavioral health services were either rationed or insufficiently delivered."

-New Mexico Medicaid official

subcontractors to operate on site in $\mathrm{MCO}$ offices to facilitate coordinated management. ${ }^{30}$

To ensure that funding for behavioral health services is not diverted to physical health care or plan administration, states are considering including in plan contracts minimum medical loss ratios for behavioral health services. In addition to such a provision, New York is including a transitional provision requiring MCOs to pay ambulatory behavioral health providers at their current fee-for-service rates for two years after the carve-in is implemented. ${ }^{31}$ This measure is intended to preserve funding to meet beneficiary needs and help small behavioral health providers making the transition to managed care contracting, with which they have little experience.

Special models for people with serious mental illness or SUDs. Stakeholders expressed the greatest concerns with respect to MCOs taking on responsibility for behavioral health services for individuals with serious mental illness or SUDs. At the same time, there was widespread recognition that these individuals need integrated care. Accordingly, states are beginning to develop capitated models specifically for high-need patients and requiring health plans to meet enhanced standards.

In April 2014, Arizona implemented an integrated physical and behavioral health benefit for Medicaid enrollees with serious mental illness in one county through a regional $\mathrm{BHO} .^{32}$ Likewise, in July 2014, Florida implemented a fully integrated health plan through a BHO for residents with mental illness, starting in Miami-Dade and Broward counties and rolling out to other regions in September. ${ }^{33}$ In 2015, New York will introduce Health and Recovery Plans (HARPs), an integrated managed care product for individuals with serious mental illness or SUDs, plus high-risk utilization patterns or functional deficits. ${ }^{34}$ HARPs will be subject to more extensive behavioral health staffing and experience requirements than those for MCOs enrolling individuals with less serious behavioral health needs. HARPs also will be required to provide an enhanced benefit package that includes recovery-oriented home- and community-based services, such as employment and education supports, as well as all physical and behavioral health services.

By creating what are in effect special needs plans for individuals with serious behavioral health issues, states are able to vest in a single managed care entity responsibility for the full range of services that address the physical, behavioral health, and social needs of especially needy populations, and at the same time impose additional experiential requirements. These models are gaining interest among stakeholders who are anxious to see integrated models extended to populations with serious mental illness or SUDs, but are concerned that traditional MCOs are ill-equipped to manage these populations. One notable reservation with respect to this approach is a concern about the potentially stigmatizing effect of a separate delivery system for people with serious behavioral health conditions.

\section{REGULATORY REQUIREMENTS}

No matter how cohesive the administration and purchasing of Medicaid physical and behavioral health services, state regulatory policies with respect to licensing, certification, and reimbursement may stymie integration at the provider level.

\section{Licensing and Certification}

In states across the country, providers report that "licensing and administration have not kept pace with provider practices," often impeding integrated care. ${ }^{35} \mathrm{It}$ is not unusual for providers seeking to colocate physical, mental health, and SUD services to require licenses from multiple agencies, each of which has its own licensing policies and procedures. ${ }^{36}$ This is at best an expensive burden for providers and at worst a deterrent to colocation of services. 
In Massachusetts, state regulations require new or renovated facilities to provide separate waiting rooms for physical and behavioral health services, which not only stigmatizes behavioral health patients but also discourages integration among providers with limited space. ${ }^{37}$ Recently, the state has granted waivers of these requirements to enable integration. Similarly, Arizona state officials noted that, until recently, colocation of physical and behavioral health services in the same space was not permitted. ${ }^{38}$ Under new rules in Arizona, a wide range of facilities, including outpatient treatment centers, can provide both physical and behavioral health services under a single license. ${ }^{39}$

Professional credentialing rules similarly can impede integrated care. Integrated care models increasingly rely on "nontraditional" providers, including community health workers, patient navigators, and peer counselors. If such providers are not credentialed, their services may not be covered by Medicaid. ${ }^{40}$ To facilitate the employment of nontraditional staff, New York, for example, is establishing a program that will enable certified peer advocates to deliver Medicaid-reimbursable services in outpatient clinic settings certified by the state's SUD agency. $^{41}$

\section{Billing Requirements}

Medicaid billing rules also affect integrated care delivery. One policy relates to whether a provider may bill for both a behavioral health and physical health visit on the same day, something that might well be important in caring for patients with comorbid conditions. In 2010, 30 states and the District of Columbia allowed same-day billing for physical and behavioral health visits in federally qualified health centers. Fourteen states did not allow same-day billing by any providers, and three states allowed same-day billing in fee-for-service Medicaid outside of health centers. ${ }^{42}$ States that decline to permit same-day billing at health centers point to federal rules that bar them from discounting payment for the second visit to account for efficiencies related to providing multiple services in the same day. ${ }^{43}$

Additionally, many state Medicaid agencies do not allow the use of billing codes for emerging
“Existing licensing requirements are duplicative, necessitating separate licenses, redundant reporting, separate structures, separate hallways, and separate bathrooms for colocated services."

-Arizona behavioral health official

treatments. For example, since at least 2011, the Substance Abuse and Mental Health Services Administration has recommended use of Screening, Brief Intervention, and Referral to Treatment, an evidence-based practice used to screen for, reduce, and prevent problematic substance use in physical health settings. ${ }^{44}$ However, by 2012, just 16 state Medicaid agencies had developed a billing code for this practice. ${ }^{45}$

Primary care providers face broader challenges related to billing for integrated care because of state rules limiting when and how they may bill for behavioral health services. For example, some states limit the types of practitioners who may bill for behavioral health services, or the procedures and diagnoses codes for which primary care practices may receive reimbursement. ${ }^{46}$ Providers may work around billing limitations by recording patients' secondary, reimbursable physical health diagnosis rather than their primary nonreimbursable behavioral health diagnosis in claims and patient records. Among other things, this practice results in inaccurate treatment records and confusion among providers.

\section{Data Exchange}

Exchange of physical and behavioral health diagnosis and treatment information among providers is a pillar of integrated care. Two issues make this especially difficult with respect to behavioral health services: lack of information technology and constraints on sharing behavioral health data across practices and agencies.

Behavioral health providers lag physical health providers in adoption of electronic health records (EHRs). They have limited access to capital and are mostly ineligible to receive financial incentives under the Health Information Technology for Economic and 
Clinical Health Act (only psychiatrists and nurse practitioners are eligible). Only about 2 percent of behavioral health providers were able to meet federal meaningfuluse standards for EHRs in 2011, and only 5 percent anticipated being able to do so by the end of $2012 .{ }^{47} \mathrm{By}$ comparison, more than 50 percent of office-based physicians could meet 12 stage-one meaningful-use core objectives (out of a total of 15) in 2012. ${ }^{48}$

In 2012 and 2013, New York sought to address the lack of EHRs among behavioral health providers in its Health Home program by providing funding to Regional Extension Centers to offer technical assistance to those providers. ${ }^{49}$

Additionally, federal and state privacy laws place more stringent restrictions on behavioral health information exchange than on physical health information exchange. Particularly onerous is a federal regulation (42 CFR Part 2) that prohibits federally assisted alcohol and drug use programs from sharing SUD records for treatment, payment, or health care operations purposes without written patient consent, except in the event of medical emergencies. In May 2014, the federal government announced its intent to update these regulations, acknowledging the barriers they create to integrated care delivery, but also noting the continuing need to protect personal information from inappropriate disclosures. ${ }^{50}$

Regardless of federal action, strategies are available to states to support greater exchange of information among physical and behavioral health providers, while protecting patient privacy. ${ }^{51}$ States can clarify privacy law through agency guidance, streamline privacy standards by offering a single set of requirements for all protected information, and develop standardized, multiprovider consent forms for the exchange of information. For example, the North Carolina Health Information Exchange Act supersedes other state privacy laws within the state health information exchange, allowing information sharing in accordance with federal standards. This law also provides immunity from liability for providers who, in good faith, rely upon information provided through the network. To streamline beneficiary consent to information-sharing in its Health Home program, New York has a standard consent form covering all information obtained by providers through the state's Regional Health Information Organizations. ${ }^{52}$

\section{CONCLUSION}

There is little dispute that Medicaid patients fare best when their physical and behavioral health needs are addressed in tandem, coordinated by a single professional or team of professionals. For states, the question is how best to support providers in achieving this goal. With Medicaid's increasingly important role in health care reform generally and in the payment and delivery of behavioral health services specifically, states are taking action to eliminate system-level impediments to the delivery of integrated care by revising their administrative, purchasing, financing, and regulatory structures. No single strategy will address every barrier to integrated care and different strategies will work in different states; however, all states have powerful levers through which to promote integrated care. 


\section{NOTES}

1 Truven Health Analytics, National Expenditures for Mental Health Services and Substance Abuse Treatment, 1986-2009, No. SMA-13-4740 (Rockville, Md.: Substance Abuse and Mental Health Services Administration, April 2013), accessed March 26, 2014, http://store.samhsa.gov/shin/content//SMA13-4740/ SMA13-4740.pdf.

2 C. Boyd, B. Leff, C. Weiss et al., Clarifying Multimorbidity Patterns to Improve Targeting and Delivery of Clinical Services for Medicaid Populations (Hamilton, N.J.: Center for Health Care Strategies, Inc., Dec. 2010), accessed March 26, 2014, http://www.chcs.org/usr_doc/clarifying_multimorbidity_patterns.pdf.

3 J. Parks, D. Svendsen, P. Singer et al., Morbidity and Mortality in People with Serious Mental Illness, Technical Report No. 13 (Alexandria, Va.: National Association of State Mental Health Program Directors, Oct. 2006), accessed March 26, 2014, http://www.nasmhpd.org/ docs/publications/MDCdocs/Mortality\%20and\%20 Morbidity\%20Final\%20Report\%208.18.08.pdf.

4 Healthcare.gov, "24 States Are Refusing to Expand Medicaid. Here's What That Means for Their Residents," accessed March 26, 2014, http://www.whitehouse.gov/ share/medicaid-map.

5 M. Regenstein and S. Rosenbaum, "What the Affordable Care Act Means for People with Jail Stays," Health Affairs, March 2014 33(3):448-54; S. A. Somers, E. Nicolella, A. Hamblin et al., "Medicaid Expansion: Considerations for States Regarding Newly Eligible JailInvolved Individuals," Health Affairs, March 2014 33(3):455-61; J. Tsai, R. A. Rosenheck, D. P. Culhane et al., "Medicaid Expansion: Chronically Homeless Adults Will Need Targeted Enrollment and Access to a Broad Range of Services," Health Affairs, Sept. 2013 32(9):1552-59; and Substance Abuse and Mental Health Services Administration, Enrollment Under the Medicaid Expansion and Health Insurance Exchanges: $A$ Focus on Those with Behavioral Health Conditions in New York (Rockville, Md:: SAMHSA, 2012), accessed March 26, 2014, http://store.samhsa.gov/shin/content//PEP13BHPREV-ACA/NSDUH_state_profile_New_York_508_ final_extra.pdf.
6 State Medicaid Director Letter on the Application of the Mental Health Parity and Addiction Equity Act to Medicaid MCOs, CHIP and Alternative Benefit Plans, Jan. 2013, at http://www.medicaid.gov/federal-policyguidance/downloads/sho-13-001.pdf.

7 Substance Abuse and Mental Health Services Administration, Results from the 2010 National Survey on Drug Use and Health: Mental Health Findings (Rockville, Md.: SAMHSA, Jan. 2012), accessed March 26, 2014, http://www.samhsa.gov/data/NSDUH/ 2k10MH_Findings/2k10MHResults.htm; Parks, Svendsen, Singer et al., Morbidity and Mortality, 2006; M. Lindsey, W. Patterson, K. Ray et al., Potentially Preventable Hospital Readmissions Among Medicaid Recipients with Mental Health and/or Substance Abuse Health Conditions Compared with All Others: New York State, 2007, Statistical Brief No. 3 (Albany, N.Y.: New York State Department of Health, n.d.), accessed March 26, 2014, http://www.health.ny.gov/health_care/managed_care/ reports/statistics_data/3hospital_readmissions_mentahealth.pdf; and Kaiser Commission on Medicaid and the Uninsured, The Role of Medicaid for People with Behavioral Health Conditions (Washington, D.C.: Kaiser Commission on Medicaid and the Uninsured, Nov. 2012), accessed March 26, 2014, http://kaiserfamilyfoundation.files.wordpress.com/2013/01/8383_bhc.pdf.

8 J. Unützer, W. Katon, C. M. Callahan et al., "Collaborative Care Management of Late-Life Depression in the Primary Care Setting: A Randomized Controlled Trial," Journal of the American Medical Association, Dec. 11, 2002 288(22):2836-45, accessed March 26, 2014, http://jama.jamanetwork.com/data/ Journals/JAMA/4859/JOC21093. pdf; J. Unützer, W. J. Katon, M. Y. Fan et al., "Long-Term Cost Effects of Collaborative Care for Late-Life Depression," American Journal of Managed Care, Feb. 2008 14(2):95-100, accessed March 26, 2014, http://www.ncbi.nlm.nih.gov/ pmc/articles/PMC3810022/pdf/nihms-521130.pdf; and M. Butler, R. L. Kane, D. McAlpine et al., Integration of Mental Health/Substance Abuse and Primary Care, Evidence Report/Technology Assessment No. 173 (Rockville, Md.: Agency for Healthcare Research and Quality, Oct. 2008), accessed March 26, 2014, http:// www.ahrq.gov/research/findings/evidence-basedreports/mhsapc-evidence-report.pdf. 
See, for example, A. Hamblin, J. Verdier, and M. Au, State Options for Integrating Physical and Behavioral Health Care (Baltimore: Integrated Care Resource Center, Oct. 2011), accessed March 26, 2014, http:// www.integratedcareresourcecenter.com/pdfs/ICrC_bh_ briefing_document_1006.pdf; C. J. Peek and The National Integration Academy Council, Lexicon for Behavioral Health and Primary Care Integration: Concepts and Definitions Developed by Expert Consensus, AHRQ Publication No. AHRQ 13-IPO01-EF (Rockville, Md.: Agency for Healthcare Research and Quality, 2013), accessed May 1, 2014, http://integrationacademy.ahrq. gov/sites/default/files/Lexicon.pdf; and B. Heath, P. Wise Romero, and K. Reynolds, A Standard Framework for Levels of Integrated Healthcare (Washington, D.C.: SAMHSA-HRSA Center for Integrated Health Solutions), accessed May 1, 2014, http://www.integration.samhsa.gov/integrated-care-models/A_Standard_ Framework_for_Levels_of_Integrated_Healthcare.pdf.

10 T. C. Lutterman, A. Berhane, R. Shaw et al., Funding and Characteristics of State Mental Health Agencies, 2010 (Rockville, Md.: Substance Abuse and Mental Health Services Administration, 2011), accessed March 26, 2014, http://www.aahd.us/wp-content/ uploads/2012/12/ FundingStateMentalHealthAgencies2010.pdf.

11 National Association of Medicaid Directors, State Medicaid Operations Survey: Second Annual Survey of Medicaid Directors (Washington, D.C.: NAMD, Feb. 2014), accessed March 26, 2014, http://medicaiddirectors.org/sites/medicaiddirectors.org/files/public/ops_survey.pdf.

12 Manatt Health Solutions interview with New York State provider, Jan. 23, 2014.

13 California Statutes of 2011, Chapter 32, Assembly Bill 106, accessed March 26, 2014, http://www.leginfo.ca. gov/pub/11-12/bill/asm/ab_0101-0150/ab_106_ bill_20110629_chaptered.html; and California Senate Rules Committee, Bill Analysis - Budget Act of 2011: Health (Sacramento, Calif.: California Senate Rules Committee, June 2011), accessed March 26, 2014, http://www.leginfo.ca.gov/pub/11-12/bill/asm/ab_01010150/ab_102_cfa_20110609_094935_sen_floor.html.

14 E. G. Brown, Government Reorganization Plan (Sacramento, Calif.: Office of Governor Edmund G. Brown, March 2012), accessed March 26, 2014, http:// gov.ca.gov/docs/Cover_Letter_and_Summary.pdf.
15 S. Sullivan, "ERO 41," Presentation before the Senate Ways and Means Committee, Feb. 15, 2012, accessed March 26, 2014, http://media.khi.org/news/documents/2012/02/15/KDoA_ERO_41.pdf; and Kansas Department for Aging and Disability Services, "KanCare Information Sessions: Focusing on KDADS Programs," Presentation at KanCare information sessions, Aug. 21-31, 2012, accessed April 8, 2014, http://www.kancare.ks.gov/download/KDADS_Specific_KanCare_ Presentations_August_2012.pdf.

16 Agencies assuming contracting and purchasing responsibility, however, may have limited experience with new service types and limited relationships with key stakeholders, making continuing interagency cooperation critical. For this reason, New York State envisions "team oversight" of Medicaid managed care contracts across the Department of Health and the state's behavioral health agencies, even as the Department of Health holds the MCO contracts (Manatt Health Solutions interview with New York State Medicaid and behavioral health officials, Jan. 21, 2014). Similarly, in Arizona, the Medicaid agency is assisting the Division of Behavioral Health Services with development of contract provisions and oversight with respect to physical health services (Manatt Health Solutions interview with Arizona provider, Jan. 21, 2014).

17 Participant comments at Advisory Group meeting, Feb. 25, 2014.

18

19

20

L. Summer and J. Hoadley, The Role of Medicaid Managed Care in Health Delivery System Innovation (New York: The Commonwealth Fund, April 2014), p. 13.

See, e.g., Washington State Department of Social and Health Services, "Contract Amendment: PIHP Amendment [with North Sound Regional Support Network]," Contract No. 1169-36766, Amendment No. 3, Aug. 29, 2012, accessed March 26, 2014, http://www. nsmha.org/contracts/dshs/DSHS_Medicaid_and_SMHC/ Amendments/DSHS-NSMHA-PIHP-11-13_1169-36766-03. pdf, and Washington State Health Care Authority, "Managed Care Contract: Basic Health and Healthy Options," 2012, accessed March 26, 2014, http://www. hca.wa.gov/Documents/managed_care/2012BH-HOFinalContract.pdf. 
Maryland Department of Health and Mental Hygiene, "Request for Proposals: Solicitation No. DHMH OPASS-14-13835. Administrative Services Organization for Maryland's Public Behavioral Health System," Feb. 4, 2014, accessed March 26, 2014 , https://emaryland.buyspeed.com/bso/external/bidDetail. sdo?docld=MDM0031012802\&external=true\&parentUrl= bid. New Mexico Human Services Department, Centennial Care 1115 Waiver Amendment Request, April 25, 2012, accessed April 8, 2014, http://www.hsd.state.nm.us/ uploads/FileLinks/f1a11ad705c94ea59ef5107bb672075a/ Centennial_Care__Waiver_Submission_to_CMS.pdf.

25 Manatt Health Solutions interview with New York State Medicaid official, Jan. 15, 2014.

26 63rd Washington State Legislature, 2014 Regular Session, Senate Bill 6312, accessed March 26, 2014 , http://apps.leg.wa.gov/documents/billdocs/2013-14/Pdf/ Bills/Senate\%20Passed\%20Legislature/6312-S2.PL.pdf.

27 Participant comments at Advisory Group meeting, Feb. 25, 2014

28 W. Holt and R. Dougherty, Increasing Access to Behavioral Healthcare: Managed Care Options and Requirements (Washington, D.C.: National Council for Community Behavioral Health, July 2011), accessed March 26, 2014, http://www.thenationalcouncil.org/wpcontent/uploads/2013/01/Increasing-Access-toManaged-Care-Report.pdf.

29 New Mexico Human Services Department. "Amended and Restated Medicaid Managed Care Services Agreement Among New Mexico Human Services Department, New Mexico Behavioral Health Purchasing Collaborative and HCSC Insurance Services Company, Operating as Blue Cross and Blue Shield of New Mexico," n.d., accessed March 26, 2014, http://www. hsd.state.nm.us/uploads/files/Looking\%20For\%20 Information/General\%20Information/Contracts/ Medical\%20Assistance\%20Division/MCOs\%20-\%20 Centennial\%20Care/BCBSNM\%20Contract\%20 Amendment\%20\%231.pdf.

Hamblin, Verdier, and Au, State Options, 2011.
31 State of New York, "New York Request for Qualifications for Behavioral Health Benefit Administration: Managed Care Organizations and Health and Recovery Plans," Dec. 5, 2013, accessed March 26, 2014, http://www.health.ny.gov/health_care/ medicaid/redesign/docs/2013-12-5_draft_man_care_ rfq_pub_review.pdf.

32 Manatt Health Solutions interview with Arizona behavioral health official, Dec. 18, 2013.

33 P. Galewitz, "Florida Shifts Medicaid Mental Health Strategy," Kaiser Health News, July 7, 2014.

34 State of New York, "New York Request for Qualifications," 2013.

35 Manatt Health Solutions interview with Arizona provider, Jan. 21, 2014

36 Hospital outpatient departments and diagnostic and treatment centers fall under Article 28 of the Public Health Law, mental health agencies fall under Article 31 of the Mental Hygiene Law, and SUD service agencies fall under Article 32 of the Mental Hygiene Law.

37 Behavioral Health Integration Task Force, Report to the Legislature and the Health Policy Commission (Boston: Behavioral Health Integration Task Force, July 2013), accessed April 9, 2014, http://www.massneuropsych. org/wp-content/uploads/2013/06/Behavioral-HealthIntegration-Task-Force-Final-Report-andRecommendations_July-2013.pdf.

38 B. Lang, "Breaking Down Barriers: Supporting Physical and Behavioral Health Through Licensing Rules," Presentation at Public Forum Moving Forward: Implementing Integrated Models of Care in Arizona, Aug. 24, 2012, accessed April 30, 2014, http://www.azdhs. gov/diro/documents/forums/2012/breaking-down-barriers.pdf; and 50th Arizona Legislature, First Regular Session, House Bill 2634: An Act Prescribing Adoption of Department Of Health Services Health Care Institution Rules, 2011, Chapter 96, accessed March 26, 2014, http://www.azleg.gov/FormatDocument. asp?inDoc=/legtext/50leg/1r/laws/0096.htm\&Session_ ID $=102$.

39 Arizona Department of Health Services, "Public Health Services Licensing-Classification Structure \& Licensing Process Crosswalk," n.d., accessed March 26, 2014, http://www.azdhs.gov/als/integrated/documents/classification-structure-crosswalk.pdf. 
Nardone, Snyder, and Paradise, Integrating Physical and Behavioral Health Care, 2014.

${ }^{41}$ New York State Office of Alcoholism and Substance Abuse Services, "Commissioner Arlene GonzálezSánchez Announces Peer Advocate Certificate in New York," June 19, 2013, accessed March 26, 2014, https:// www.oasas.ny.gov/pio/press/20130619PeerAdCert.cfm.

42 M. Brolin, A. Quinn, J. T. Sirkin et al., Financing of Behavioral Health Services Within Federally Qualified Health Centers (Washington, D.C.: Truven Health Analytics, July 2012), accessed March 26, 2014, http:// www.integration.samhsa.gov/Financing_BH_Services_at_ FQHCs_Final_7_23-12.pdf.

43 Social Security Act 1902(bb). Notably, it is the federal rule barring states from discounting reimbursement to FQHCs (even to reflect efficiencies related to same-day visits) that states cite as one of the bases of the sameday billing rule. See T. M. Westmoreland, SMDL \#O1014 (Baltimore: Centers for Medicare and Medicaid Services, Jan. 19, 2001), accessed April 9, 2014, http:// downloads.cms.gov/cmsgov/archived-downloads/SMDL/ downloads/smd011901d.pdf.

44 Substance Abuse and Mental Health Services Administration, Screening, Brief Intervention and Referral to Treatment (SBIRT) in Behavioral Healthcare (Rockville, Md.: SAMHSA, April 1, 2011), accessed April 9, 2014, http://www.samhsa.gov/prevention/sbirt/ SBIRTwhitepaper.pdf.

SAMHSA-HRSA Center for Integrated Health Solutions, SBIRT: Screening, Brief Intervention, and Referral to Treatment-Opportunities for Implementation and Points for Consideration (Washington, D.C.: SAMHSA-HRSA Center for Integrated Health Solutions, June 2012), accessed March 26, 2014, http:// www.integration.samhsa.gov/SBIRT_Issue_Brief.pdf.

${ }^{46}$ C. Kautz, D. Mauch, and S. A. Smith, Reimbursement of Mental Health Services in Primary Care Settings, HHS Publication No. SMA-08-4324 (Rockville, Md.: Substance Abuse and Mental Health Services Administration, 2008), accessed May 7, 2014, http:// www.integration.samhsa.gov/Reimbursement_of_ Mental_Health_Services_in_Primary_Care_Settings.pdf.
47 National Council for Community Behavioral Health, HIT Adoption and Readiness for Meaningful Use in Community Behavioral Health: Report on the 2012 National Council Survey (Washington, D.C.: National Council, June 2012), accessed March 26, 2014, http://www.thenationalcouncil.org/wp-content/uploads/2012/10/HIT-Survey-FullReport.pdf.

48 J. King, V. Patel, and M. F. Furukawa, Physician Adoption of Electronic Health Record Technology to Meet Meaningful Use Objectives: 2009-2012, ONC Data Brief No. 7 (Washington, D.C.: Office of the National Coordinator for Health Information Technology, Dec. 2012), accessed April 9, 2014, http://www.healthit.gov/ sites/default/files/onc-data-brief-7-december-2012.pdf.

49 New York eHealth Collaborative and NYC Regional Electronic Adoption Center for Health, "HEAL 22 Grant: Health Information Technology and Exchange for Behavioral Health," Webinar presentation, Nov. 19, 2012, accessed March 26, 2014, http://nyehealth.org/ wp-content/uploads/2013/01/HEAL-22-Slides-11-19Health-Home-EHR-Webinar.pdf.

50

Substance Abuse and Mental Health Services Administration, Confidentiality of Alcohol and Drug Abuse Patient Records, Notice of Public Listening Session, May 12, 2014.

51 W. Bernstein, R. Belfort, and S. Ingargiola, Integrating Physical and Behavioral Health: Strategies for Overcoming Legal Barriers to Health Information Exchange (Princeton, N.J.: Robert Wood Johnson Foundation, Jan. 2014), accessed March 26, 2014, http://www.manatt.com/ uploadedFiles/Content/4_News_and_Events/ Newsletters/IntegratingPhysicalandBehavioralHealth.pdf; and Colorado Regional Health Information Organization, Supporting Integration of Behavioral Health Care Through Health Information Exchange: Recommendations for Integrating Colorado's Mental Health, Substance Use Treatment, and Medical Communities Through the Development of Statewide HIE (Denver: CORHIO, April 2012), accessed April 30, 2014, http://www.corhio.org/media/40757/supporting_integration_of_behavioral_health_care_through_hie_ april_2012-web.pdf. New York State Department of Health, "Health Home Patient Information Sharing Consent," No. DOH-5055, Nov. 2012, accessed March 26, 2014, https://www. health.ny.gov/forms/doh-5055.pdf. 

- 0 The COMMONWEALTH FUND 